\title{
DANO AMBIENTAL: SEM LEI NÃO HÁ DANO?
}

\author{
Fúlvia Leticia Perego Silva ${ }^{1}$, Munir Jorge Felício ${ }^{2}$ \\ ${ }^{1}$ Integrante do Núcleo de Estudos Ambientais e Geoprocessamento - NEAGEO do Mestrado em Meio Ambiente e \\ Desenvolvimento Regional - MMDRE da Universidade do Oeste Paulista - UNOESTE. ${ }^{2}$ Docente do Mestrado em Meio \\ Ambiente e Desenvolvimento Regional - MMDRE - da Universidade do Oeste Paulista - UNOESTE. E-mail: . \\ (fulvialeticia.adv@uol.com.br)
}

\section{RESUMO}

O presente artigo tem por objetivo fazer uma reflexão sobre o dano ambiental perante a legislação brasileira, bem como sobre sua existência e consequências no ordenamento jurídico anterior às leis ambientais. É sabido que o dano ambiental acompanha o homem desde sua mais remota existência no planeta Terra, mas apenas recentemente iniciou-se a construção da chamada consciência ambiental, face os graves problemas ambientais em todo o mundo. No Brasil, a primeira lei ambiental protetiva surgiu na década de 1980. Com o advento da Constituição Federal, em 1988, o meio ambiente passou a ser tutelado como um direito fundamental e considerado um bem coletivo. Neste contexto, mereceram atenção especial os chamados danos ambientais continuados, cujos efeitos danosos se perpetuam no tempo, atingindo as gerações futuras. São considerados, portanto, imprescritíveis, passíveis de reparação por meio de ações indenizatórias, individuais ou coletivas, mesmo tendo ocorrido antes da legislação ambiental.

Palavras-chaves Dano ambiental. Meio ambiente. Bem jurídico. Dano ambiental continuado. Imprescritibilidade.

\section{INTRODUÇÃO}

O dano ambiental está atrelado à existência humana na terra, não sendo, fenômeno atual. Milaré (2011) ressalta que a devastação ambiental "é um fenômeno que acompanha o homem desde os primórdios de sua história. Apenas a percepção jurídica desse fenômeno - até como consequência de um bem jurídico novo denominado 'meio ambiente' - é que é recente".

O século XX foi marcado pelo desenvolvimento acentuado das mais diversas tecnologias e pelo nascer da globalização. Nesse cenário, a questão ambiental tem um papel fundamental e essencial na preservação do Planeta, especialmente pelo fato de que sua ocorrência desconhece fronteiras geográficas de todo tipo.

Durante séculos governos e empresas exploram recursos naturais de forma desenfreada, em razão de uma economia predominantemente consumista. Tal condição provoca enorme dificuldade no controle de danos ambientais em todos os cantos do mundo.

Com a tomada de consciência dos problemas ambientais a serem enfrentados - o que se deu a partir da segunda metade do século XX - buscou-se o fortalecimento do Direito 
Internacional como forma de solução de conflitos e adoção de medidas eficazes à preservação do Planeta.

Entre avanços e retrocessos, é possível afirmar que alguns progressos foram alcançados em âmbito mundial. Todavia, incumbe a cada Estado, antes de tudo, adotar uma política eficiente de proteção ao meio ambiente dentro de seus limites territoriais, para que uma integração global satisfatória seja atingida.

No Brasil, a primeira legislação de proteção ao meio ambiente surgiu na década de 1980, com a Lei n. 6.938/81, que criou a Política Nacional do Meio Ambiente. Mas foi em 1988, com a entrada em vigor da Constituição Federal, que o meio ambiente passou a ser tutelado como um direito fundamental da sociedade.

Em meio aos diversos problemas ambientais que se verificam em nosso País, importa refletir sobre a questão do dano ambiental, sempre à luz de aspectos jurídicos anteriores e posteriores à nossa legislação ambiental, posto que o dano ambiental atinge não só o bem jurídico ambiental, mas também outros interesses jurídicos.

Dessa forma, o presente artigo tem por objetivo fazer uma reflexão sobre o dano ambiental perante a legislação brasileira, bem como sobre sua existência e consequências no ordenamento jurídico anterior às leis ambientais.

Utilizou-se neste trabalho, como metodologia, pesquisas documental e bibliográfica, por meio das quais reunimos o maior número possível de informações. É nossa intenção possibilitar debates conceituais que ampliem a compreensão do dano ambiental já definido pela nossa legislação vigente, bem como daquele ainda não previsto, como forma de criar condições para a prevenção, o reparo e a proteção dos recursos naturais.

\section{CONCEITO DE DANO AMBIENTAL}

Antes de avançar para a definição de dano ambiental, é necessário, definir o que vem a ser 'dano', tendo em vista que este é pressuposto indispensável para a teoria jurídica da responsabilidade ambiental. Sendo assim:

O dano é o prejuízo injusto causado a terceiro, gerando obrigação de ressarcimento. A ação ou omissão de um terceiro é essencial. Desnecessário dizer que, no conceito, somente se incluem as alterações negativas, pois não há dano se as condições forem alteradas para melhor, sem prejuízo. É a variação, moral ou material, negativa que deverá ser, na medida do possível, mensurada de forma que se possa efetivar o ressarcimento (ANTUNES, 2013, p. 539). 
Dano é toda ofensa a bens ou interesses alheios protegidos pela ordem jurídica. O interesse, nesta concepção, representa a posição de uma pessoa, grupo ou coletividade em relação ao bem suscetível de satisfazerIhe uma necessidade. Bem deve ser entendido, em sentido amplo, como o meio de satisfação de uma necessidade. Pelo que se depreende desta definição, dano abrange qualquer diminuição ou alteração de bem destinado à satisfação de um interesse. Isso significa, como regra, que as reparações devem ser integrais, sem limitação quanto à sua indenização, compreendendo os danos patrimoniais e extrapatrimoniais. (...) $\mathrm{Na}$ verdade, dano é um elemento essencial à pretensão de uma indenização, pois sem este elemento não há como articular uma obrigação de reparar. (LEITE, 2012, p. 91).

Fiorillo (2013, p. 94) entende que por ser o dano um dos alicerces da responsabilidade civil, se faz necessário conceituá-lo. Sendo assim, "dano é a lesão a um bem jurídico".

Dano ambiental, por sua vez, é de definição mais complexa, por se tratar de um conceito aberto, assim como é o meio ambiente. Embora a moderna literatura jurídica brasileira encontre dificuldade em conceituá-lo, estudiosos entendem que é de suma importância sua definição.

Milaré (2011) arrisca um conceito: "dano ambiental é a lesão aos recursos ambientais, com consequente degradação - alteração adversa ou in pejus - do equilíbrio ecológico e da qualidade de vida". Acrescenta ainda que a noção de dano ambiental não pode estar divorciada da visão ampla de meio ambiente, que inclui, o conjunto de elementos naturais, artificias e culturais.

Para Leite (2012), o dano ambiental constitui uma expressão ambivalente, que designa, certas vezes, alterações nocivas ao meio ambiente e outras, ainda, os efeitos que tal alteração provoca na saúde das pessoas e em seus interesses. Em sua definição:

Dano ambiental significa, em uma primeira acepção, uma alteração indesejável ao conjunto de elementos chamados meio ambiente, como, por exemplo, a poluição atmosférica; seria, assim, uma lesão ao direito fundamental que todos têm de gozar e aproveitar do meio ambiente apropriado. Contudo, em sua segunda conceituação, dano ambiental engloba os efeitos que esta modificação gera na saúde das pessoas e em seus interesses (LEITE, 2012, p. 92)

Fiorillo (2013) por sua vez afirma que:

Ocorrendo lesão a um bem ambiental, resultante de atividade praticada por pessoa física ou jurídica, pública ou privada, que direta ou indiretamente seja responsável pelo dano, não só há a caracterização deste como a identificação do poluidor, aquele que terá o dever de indenizá-lo (FIORILLO, 2013, p. 94). 
Dano ambiental para Antunes (2013) "é dano ao meio ambiente", portanto, "é a ação ou omissão que prejudique as diversas condições, leis, influências e interações de ordem física, química e biológica que permita, abrigue e reja a vida, em quaisquer de suas formas" (ANTUNES, 2013, p. 539).

\section{O dano ambiental no ordenamento jurídico brasileiro}

A Lei no 6.938/81, que dispõe sobre a Política Nacional do Meio Ambiente, é o primeiro grande marco em termos de norma de proteção ambiental no Brasil. Essa legislação definiu de forma avançada e inovadora os conceitos, princípios, objetivos e instrumentos para a defesa do meio ambiente, reconhecendo, ainda, a importância do meio ambiente para a vida e para a qualidade de vida.

O legislador brasileiro não definiu expressamente dano ambiental, mas ofereceu suas principais características de forma abrangente e pouco objetiva, como também associou degradação à poluição.

O artigo 3ำ, inciso IV, da Lei 6.938/81, estabelece que poluidor “é a pessoa física ou jurídica, de direito público ou privado, responsável, direta ou indiretamente, por atividade causadora de degradação ambiental".

Conceitua, ainda, a degradação ambiental como a "alteração adversa das características do meio ambiente" (inciso II, do artigo 3으 da citada lei).

Assim, é importante mencionar a definição legal de poluição prevista no artigo 3으, inciso III, da Lei 6.938/81:

III - Poluição, a degradação da qualidade ambiental resultante das atividades que direta ou indiretamente:

a) prejudicam a saúde e o bem estar da população;

b) criem condições adversas às atividades sociais e econômicas;

c) afetem desfavoravelmente a biota;

d) afetem as condições estéticas e sanitárias do meio ambiente;

e) lancem matéria ou energia em desacordo com os padrões ambientais estabelecidos.

A legislação define poluidor como a pessoa (física ou jurídica) causadora da degradação ambiental, por conseguinte, poluidor é o degradador ambiental ou a pessoa que altera adversamente as características do ambiente.

O tratamento legal atribuído a esses conceitos jurídicos: poluidor, poluição e degradação ambiental, dá ensejo a afirmação de que a poluição não está restrita à alteração do meio natural, 
portanto, o meio ambiente a ser considerado pode ser tanto o natural, quanto o cultural e o artificial.

Logo, o dano é um pressuposto da obrigação de reparar e, consequentemente, um elemento necessário para a configuração do sistema de responsabilidade civil. Já a definição de dano ambiental abrange qualquer lesão ao bem jurídico-meio ambiente, causada por atividades ou condutas de pessoas físicas ou jurídicas.

Após análise na lei brasileira, Leite (2012) concluiu que:

O dano ambiental deve ser compreendido como toda lesão intolerável causada por qualquer ação humana (culposa ou não) ao meio ambiente, diretamente, como macrobem de interesse da coletividade, em uma concepção totalizante, e indiretamente, a terceiros, tendo em vista interesses próprios e individualizáveis e que refletem no macrobem (LEITE, 2012, p. 101-102).

A Lei da Ação Civil Pública, ou Lei no 7.347/85, tornou-se o segundo grande marco da legislação ambiental que disciplinou a ação civil pública como instrumento de defesa do meio ambiente e dos demais direitos difusos e coletivos, fazendo com que os danos ao meio ambiente pudessem efetivamente chegar ao Poder Judiciário.

O terceiro grande marco de norma ambiental veio com a promulgação da Constituição Federal de 1988, trazendo um capítulo dedicado inteiramente ao meio ambiente e em diversos outros artigos em que também tratam do assunto, alçando o meio ambiente à categoria de bem protegido constitucionalmente. Com a redação dada ao artigo $225^{1}$, o meio ambiente foi erigido à categoria de direito fundamental.

O quarto marco se deu com a Lei de Crimes Ambientais, ou Lei no 9.605/98, que dispõe sobre as sanções penais e administrativas aplicáveis às condutas e atividades lesivas ao meio ambiente. Essa Lei regulamentou instrumentos importantes da legislação ambiental como a desconsideração da personalidade da pessoa jurídica e a responsabilização penal da pessoa jurídica.

Além das referidas leis, outras mais recentes surgiram para ampliar a proteção do meio ambiente. Assim como o Direito Ambiental propriamente dito, que surge com princípios, objetivos e instrumentos peculiares.

Ao tratar da danosidade ambiental, Milaré (2011, p. 1128) ressalta a reação jurídica, chamado por ele de "materialização do princípio da responsabilidade integral do degradador, que

\footnotetext{
${ }^{1}$ Art. 225 - Todos têm direito ao meio ambiente ecologicamente equilibrado, bem de uso comum do povo e essencial à sadia qualidade de vida, impondo-se ao Poder Público e à coletividade o dever de defendê-lo e preservá-lo para as presentes e futuras gerações. 
o sujeita, cumulativamente, às sanções repressivas e reparatórias". Um ato atentatório ao ambiente poderá ter repercussão no ordenamento jurídico de três maneiras distintas: sanções administrativas, sanções criminais e sanções civis.

Além do artigo 935 do Código Civil $^{2}$ estabelecer o principio da independência da responsabilidade civil em relação à criminal, a norma constitucional já o havia incorporado para fins de defesa do meio ambiente, nos termos do paragrafo $30^{3}$, do artigo 225 da Constituição Federal, que prevê "as condutas e atividades consideradas lesivas ao meio ambiente sujeitarão os infratores, pessoas físicas ou jurídicas, a sanções penais e administrativas, independentemente da obrigação de reparar os danos causados". Também no mesmo diploma legal, nos termos do artigo 170, caput ${ }^{4}$ e inciso $\mathrm{VI}^{5}$, a ordem econômica brasileira, "fundada na valorização do trabalho humano e na livre iniciativa," adota entre seus princípios, a "defesa do meio ambiente". Já a Lei 9.605/1998 veio dispor sobre as sanções penais e administrativas derivadas de condutas e atividades lesivas ao meio ambiente.

Do texto constitucional depreende-se, com facilidade, que o dano ao meio ambiente tem repercussão jurídica em três esferas, sendo certo que o poluidor, por um mesmo ato, pode ser responsabilizado, alternativa ou cumulativamente, nas esferas penal, administrativa e civil. Assim, a proteção jurídica do meio ambiente atua na área preventiva, reparatória e repressiva.

Quanto ao tipo de sanção, essa pode ser de ordem moral (advertência), patrimonial (decorrente da responsabilidade civil) ou limitativa de liberdade, sendo que a responsabilidade adquire características e normas próprias, dependendo do âmbito no qual se a analisa.

Assim, cada um dos três âmbitos de responsabilidade tem características próprias e é regido por normas específicas. Vale dizer mais: os três tipos de responsabilidade são independentes entre si, resultando em sanções próprias de cada tipo. Esta característica, aliás, não constitui peculiaridade do dano ambiental ou ecológico, pois qualquer dano causado a um bem de interesse público pode gerar os três tipos de responsabilidade.

\footnotetext{
${ }^{2}$ Art. 935. A responsabilidade civil é independente da criminal, não se podendo questionar mais sobre a existência do fato, ou sobre quem seja o seu autor, quando estas questões se acharem decididas no juízo criminal.

${ }^{3} \S$ 3ㅇ - As condutas e atividades consideradas lesivas ao meio ambiente sujeitarão os infratores, pessoas físicas ou jurídicas, a sanções penais e administrativas, independentemente da obrigação de reparar os danos causados.

${ }^{4}$ Art. 170 - A ordem econômica, fundada na valorização do trabalho humano e na livre iniciativa, tem por fim assegurar a todos existência digna, conforme os ditames da justiça social, observados os seguintes princípios: (...)

${ }^{5} \mathrm{VI}$ - defesa do meio ambiente, inclusive mediante tratamento diferenciado conforme o impacto ambiental dos produtos e serviços e de seus processos de elaboração e prestação.
} 


\section{A imprescritibilidade do dano ambiental}

Existem danos ambientais cujos efeitos danosos se perpetuam no tempo, atingindo as gerações presentes e futuras. Esses danos representam, segundo Leite (2012, p. 199), "uma lesão de modo continuado no tempo, originários de um autor ou vários autores, provenientes de uma sucessão de atos, praticados em épocas diversas". São chamados de danos continuados.

Assim, não há que se falar na incidência das regras clássicas de prescrição, pois em matéria ambiental, diferentemente das regras de direito civil, busca-se a proteção do meio ambiente, tratando-se de um bem da coletividade. Portanto, impera a imprescritibilidade quando se trata de direitos difusos no que diz respeito ao meio ambiente.

A imprescritibilidade da pretensão de reparação do dano ambiental fundamenta-se em dois argumentos principais, segundo afirma Leite (2012, p. 202). Em primeiro lugar, o direito ao meio ambiente ecologicamente equilibrado é um direito fundamental, de caráter coletivo, que traz ínsito três qualidades: a irrenunciabilidade, a inalienabilidade e a imprescritibilidade. Irrenunciabilidade porque, em que pese não ter sido exercido de fato, não aceita renúncia apriorística; inalienabilidade porque possui titularidade pulverizada e personalíssima, de modo que é intransferível e inegociável; imprescritibilidade, por ter perfil intertemporal, consagrando entre seus beneficiários, inclusive, os incapazes e até mesmo as futuras gerações.

Em segundo lugar, uma das peculiaridades do dano ambiental é a possibilidade dos seus efeitos projetarem-se no futuro. Assim, estabelecendo prazos para o exercício da pretensão reparatória, inviabilizará a reparação ambiental, deixando o meio ambiente e as futuras gerações indefesos.

A sociedade tem o direito subjetivo de ser reparada, seja pelo tempo que fica privada da fruição do bem ou recurso ambiental afetado pela atividade danosa, seja em razão do benefício que ele proporcionava ao equilíbrio ecológico, isto é, "pelo período que mediar entre a ocorrência do dano e a integral reposição da situação anterior de equilíbrio ecológico e fruição do bem ambiental protegido". (STEIGLEDER, 2004, p. 168).

\section{CONCLUSÃO}

Como o Direito Ambiental é assunto recente, há uma falsa impressão de que a degradação ao meio ambiente é algo da modernidade. Como muito bem apontado por Milaré (2011, p. 1117) “a devastação ambiental não é privilégio de nossos dias. É um fenômeno que acompanha o homem desde os primórdios de sua história". 
De fato, os danos ambientais sempre existiram no mundo habitável; apenas recentemente o meio ambiente ganhou holofotes no mundo e, no Brasil, com a Constituição Federal de 1988, passou a ser tutelado como um direito fundamental. Nesse sentido discorrem José Rubens Morato Leite (2003); Ingo Wolfgang Sarlet e Tiago Fensterseifer (2012); e Terence Trennepohl (2009).

Um exemplo de devastação ambiental foi a construção da Usina Hidrelétrica de Capivara, no município de Taciba/SP, no Rio Paranapanema, inaugurada em 1977, que priorizou o desenvolvimento energético em prejuízo das comunidades ribeirinhas e das cidades atingidas pelo alagamento, causando grandes impactos ambientais na região. As obras foram feitas num momento em que a legislação brasileira não dispunha sobre danos ambientais.

Assim, fácil concluir que o dano ambiental faz parte da vida humana na Terra, independentemente da existência de leis. Diferentemente do instituto da reparação/indenização, que depende da previsão legal de proteção jurídica a um bem, para que se estabeleça o instituto jurídico da responsabilidade civil.

Dessa forma, a reponsabilidade por danos ao meio ambiente decorre da lesão causada a bens da coletividade, uma vez que a Constituição Federal considera o meio ambiente um "bem de uso comum do povo", conforme disposto no artigo 225 , caput. Já o paragrafo 30 , do mesmo artigo prevê que "as condutas e atividades consideradas lesivas ao meio ambiente sujeitarão os infratores, pessoas físicas ou jurídicas, a sanções penais e administrativas, independentemente da obrigação de reparar os danos causados", podendo o degradador responder na esfera criminal, cível e administrativa.

Entretanto, os danos ambientais, mesmo aqueles anteriores a legislação ambiental, que representam uma lesão de modo continuado, cujos efeitos danosos se perpetuam no tempo, atingindo as gerações presentes e futuras (como é o caso, por exemplo, das lesões causadas ao meio ambiente relativas à construção de uma Usina Hidrelétrica), devem ser reparadas, seja por meio de ações indenizatórias individuais, seja por meio de ações coletivas pelos legitimados a propô-las.

O direito ao meio ambiente ecologicamente equilibrado é um direito fundamental, de caráter coletivo, motivo que justifica a imprescritibilidade da pretensão de reparação do dano ambiental.

Portanto, mesmo não havendo legislação ambiental anterior a um dano, pelos argumentos expendidos, a sociedade tem o direito subjetivo de ser reparada, seja pelo tempo que fica privada 
da fruição do bem ou recurso ambiental afetado pela atividade danosa, seja em razão do benefício que ele proporcionava ao equilíbrio ecológico.

Percebe-se que a dificuldade não está em encontrar uma definição de dano ambiental, mas de se aplicar efetivamente a lei para que o causador do dano seja responsabilizado por uma sanção que mais aproxima o ambiente lesado do status anterior ao dano, cessando a atividade lesiva, ou adotando-se medida compensatória equivalente. O desafio está aí para os atuantes e estudiosos da área de Direito Ambiental.

\section{REFERENCIAS}

ANTUNES, Paulo de Bessa. Direito Ambiental. 15. ed. São Paulo: Atlas, 2013.

FIORILLO, Celso Antonio Pacheco. Curso de Direito Ambiental Brasileiro. 14. ed. São Paulo: Saraiva, 2013.

LEITE, José Rubens Morato. Dano Ambiental: do individual ao coletivo extrapatrimonial. 5. ed. São Paulo: Revista dos Tribunais, 2012.

MILARÉ, Édis. Direito do ambiente: a gestão ambiental em foco: doutrina, jurisprudência, glossário. 7. ed. São Paulo: Revista dos Tribunais, 2011.

SARLET, Ingo Wolfgang e FENSTERSEIFER, Tiago. Direito Constitucional Ambiental. 2. ed. São Paulo: Revista dos Tribunais, 2012.

STEIGLEDER, Annelise Monteiro. Responsabilidade civil ambiental: as dimensões do dano ambiental no direito brasileiro. Porto Alegre: Livraria do Advogado, 2004.

TRENNEPOHL, Terence. Direito Ambiental. 4. ed. Bahia: Editora Juspodivm, 2009. 